\title{
The evolution of Circular Bioeconomy: a bibliometric review
}

\author{
Maryna Yaremova ${ }^{1,{ }^{*}}$, Liudmyla Tarasovych ${ }^{1}$, Nataliia Kravchuk $^{1}$, and Olena Kilnitska ${ }^{1}$ \\ ${ }^{1}$ Polissia National University, 7 Staryi Blvd., 10008 Zhytomyr, Ukraine
}

\begin{abstract}
The aim of the article is a theoretical and methodological substantiation of the evolutionary preconditions for the formation and development of a circular bioeconomy on the basis of a bibliometric analysis of literature sources. Global problems of humanity regarding fossil fuels scarcity, environmental pollution and rapid climate change have initiated emerging a bioeconomy approach of society development focused on producing food and non-food goods based on renewable biological resources. Scientists and experts' intensification during the last decades contributed to increase in scientific works dedicated to modelling circular bioeconomy, which promoted bibliometric analysis of literature sources in several areas, including type of publication, leading journals, field of study, author, country of origin. Special attention is paid to establishing keywords complementary interconnections of circular and bioeconomy concepts and their role towards integrative paradigm. The given study allowed to identify main periods of circular bioeconomy evolution in scientific field, in particular, its emergence, transformation and advanced evolution. Recently, the conception has been prospering, which is indicated by scientific publications proliferating, profound research and introduction of innovative developments in practice.
\end{abstract}

\section{Introduction}

Modern economic science has been widely enriched by publications dedicated to bioeconomy approach of society development, which has been established due to necessity of solving global problems regarding fossil fuels scarcity, environmental pollution and climate change.

In the given context special scientists' attention is paid to gradual development of circular economy paradigm, whose idea lies in production of food and non-food goods based on renewable biological resources. Author's conception of the issue comes to availability using biotechnological developments while transforming renewable biological resources into a newly created product without harming the environment [1].

Over the last decades international mainstreaming circular bioeconomy definition to scientific terminology made necessary to carry out bibliometric analysis of literature sources according to certain criteria that will help identify paradigm conception in historical retrospect and establish changing character of basic framework.

\footnotetext{
*Corresponding author: marine182@ukr.net
} 


\section{Materials and Method}

The investigation of bio-based economy in Ukraine are still at the initial stage. Theoretical aspects of sustainable economic development are covered in the works the following domestic scientists: I. Mikhno, V. Koval, G. Shvets, O. Garmatiuk [2], K. Kostetska, N. Khumarova, Y. Umanska, N. Shmygol [3] and others. Bibliographic discourse analysis on bioeconomy issues has been carried out by such foreign scientists as: L. Staffas, M. Gustavsson, K. McCornick [4], M. Bugge, T. Hansen, A. Klitkou [5], D. D'Amato, N. Droste, B. Allen et al. [6]. It is suggested monitoring and classifying scientific works related to circular bioeconomy according to similar pattern. For this purpose, we have used Polissya National University of Ukraine open access to major international abstract databases Scopus and Web of Science, which have been chosen as our research tools (Fig. 1).

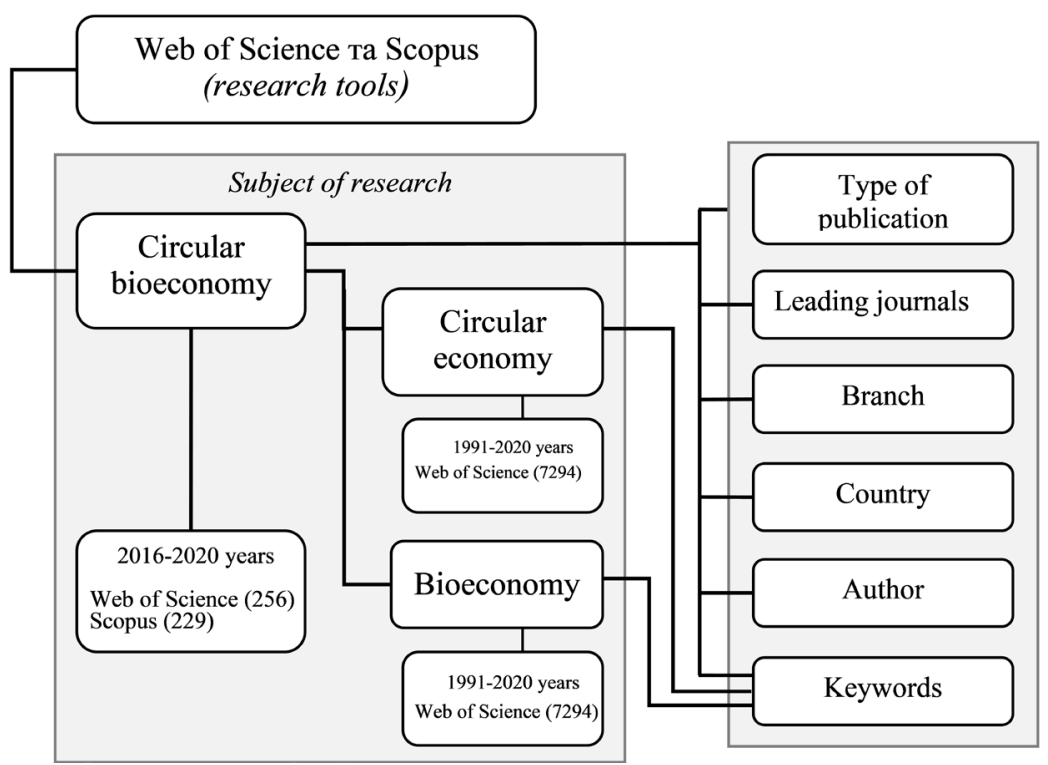

Fig. 1. Methodological model of bibliometric study on Circular Bioeconomy.

Data sources were searched through local university network by topic, publication title, its abstract or keywords «Circular Bioeconomy» taking into consideration interconnected concepts «Circular Bio-based economy» and «Circular Bio-economy», which have similar definitions.

\section{Bibliometric review of circular bioeconomy}

Study results show that first scientific works related to circular bioeconomy in Scopus and Web of Science databases appeared in 2016 (Fig. 2). 


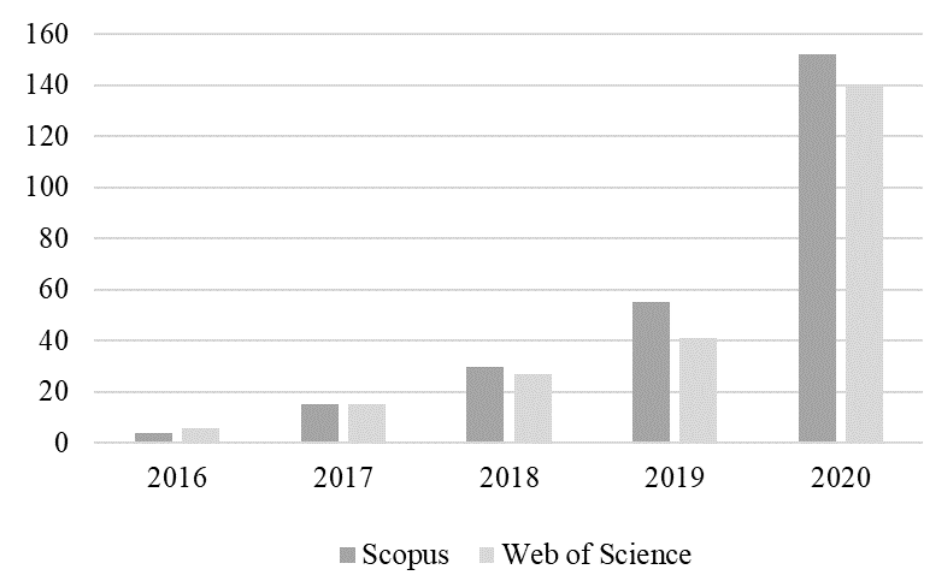

Fig. 2. Monitoring of scientific publications on Circular Bioeconomy over the period of 2016-2020 Source: built on data obtained from Scopus and Web of Science databases.

During the researched period there have been published 256 publications in Scopus database and 229 scientific papers in Web of Science database. First publications on circular bioeconomy in scientific databases were published by such outstanding scientists as: S. Mohan, S. Butti, J. Amulya, K. Dahiya, J. Modestra [7]. Gradual scientists' interest to the issue contributed to active growth of publications in 2020 that highlights relevance of the latest concept. Gradation of scientific works by type of publication is shown in Figure 3. [24].
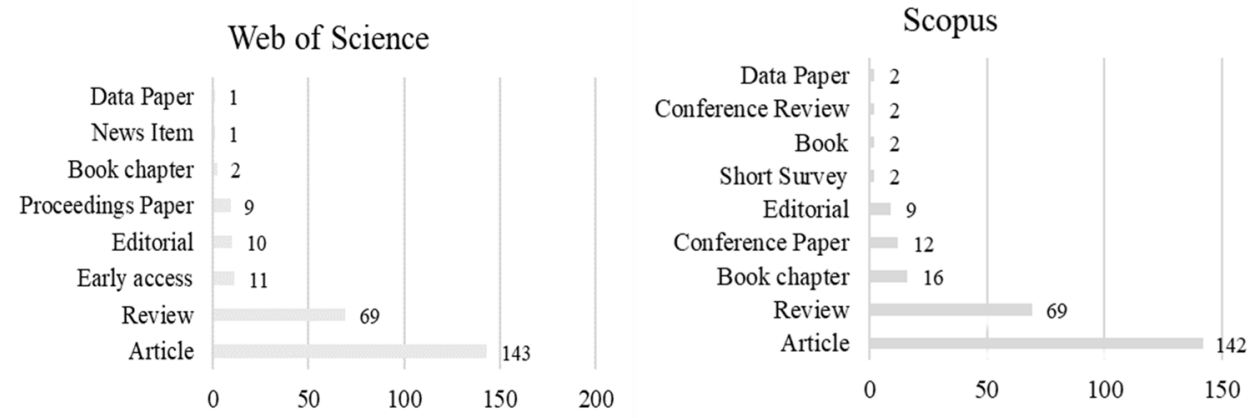

Fig. 3. Classification of scientific works on Circular Bioeconomy by type of publications over the period of 2016-2020

Source: built on data obtained from Scopus and Web of Science databases.

Most of published material on the topic of circular bioeconomy is presented by scientific articles, in particular scientometric database Scopus contains 142 publications and Web of Science - 143 .

A significant part of works are international reports (Scopus and Web of Science - 69), separate sections in monographs and textbooks (Scopus - 16 and Web of Science - 2), as well as conference abstracts (Scopus - 12 and Web of Science -9).

Taking into consideration that most of scientific papers published in databases Scopus $(55.5 \%)$ and Web of Science (62.4\%) are published in scientific journals, it is necessary to study their list by title and percentage of publications. Preferably, we have covered those periodicals that contain more than 5 documents for researched period (Table 1). 
Table 1. Publications on Circular Bioeconomy by Source title.

\begin{tabular}{|c|c|c|c|c|c|}
\hline \multirow{11}{*}{ 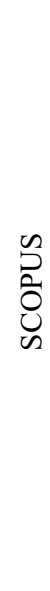 } & Source title & $\%$ & \multirow{11}{*}{ 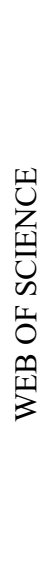 } & Source title & $\%$ \\
\hline & Bioresource Technology & 12,1 & & Bioresource Technology & 15,3 \\
\hline & Journal of Cleaner Production & 6,6 & & Journal of Cleaner Production & 7,4 \\
\hline & Sustainability Switzerland & 4,3 & & Sustainability & 4,8 \\
\hline & Forest Policy and Economics & 2,7 & & Energies & 3,0 \\
\hline & Energies & 2,3 & & Forest Policy and Economics & 3,0 \\
\hline & $\begin{array}{l}\text { Science of the Total } \\
\text { Environment }\end{array}$ & 2,3 & & $\begin{array}{l}\text { Science of the Total } \\
\text { Environment }\end{array}$ & 3,0 \\
\hline & $\begin{array}{l}\text { ACS Sustainable Chemistry } \\
\text { Engineering }\end{array}$ & 2,0 & & $\begin{array}{l}\text { ACS Sustainable Chemistry } \\
\text { Engineering }\end{array}$ & 2,2 \\
\hline & $\begin{array}{l}\text { Biofuels Bioproducts and } \\
\text { Biorefining }\end{array}$ & 1,6 & & $\begin{array}{l}\text { Biofuels Bioproducts and } \\
\text { Biorefining }\end{array}$ & 1,8 \\
\hline & $\begin{array}{l}\text { Renewable and Sustainable } \\
\text { Energy Reviews }\end{array}$ & 1,5 & & $\begin{array}{l}\text { Current Option in Green and } \\
\text { Sustainable Chemistry }\end{array}$ & 1,7 \\
\hline & Energy Procedia & 1,5 & & $\begin{array}{l}\text { Renewable and Sustainable } \\
\text { Energy Reviews }\end{array}$ & 1,7 \\
\hline
\end{tabular}

Source: built on data obtained from Scopus and Web of Science databases.

Leading economic journal in the context of circular bioeconomy is «Forest Policy and Economics», which publishes $2.7 \%$ of scientific papers from all publications of scientometric database Web of Science and 3.0\% of the total number of published materials in Scopus.

This journal and others listed in the table cover various areas of knowledge, including environmental, energy, social, economic, agricultural, etc. Scientific works systematization according to branches is shown in percentage correlation with total number in Fig. 4.

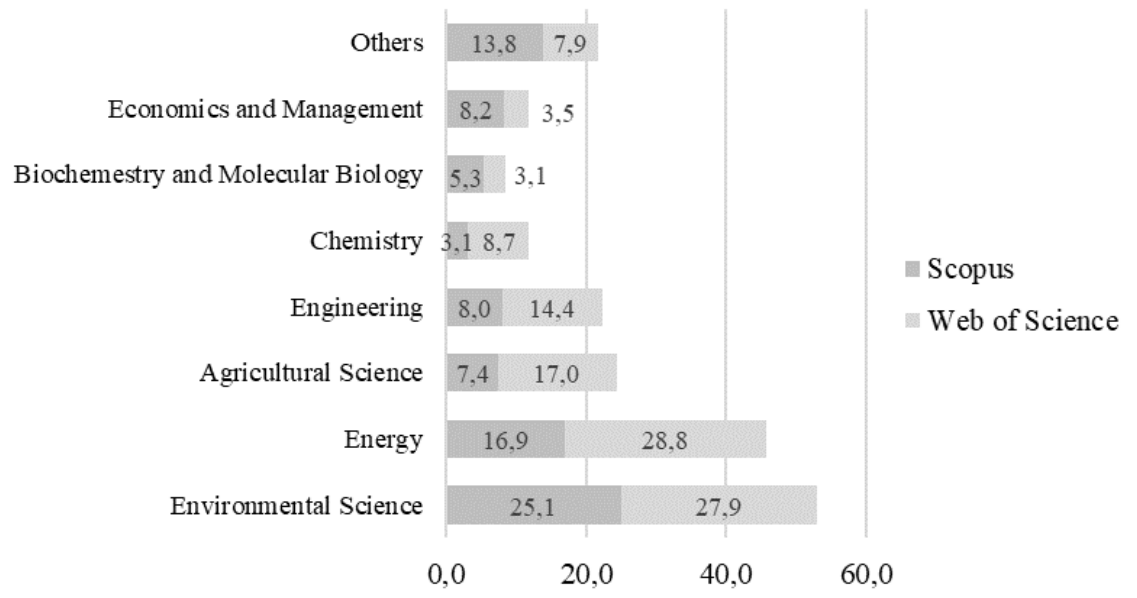

Fig. 4. Systematization of scientific works on Circular Bioeconomy by Subject area over the period of 2016-2020, \%.

Source: built on data obtained from Scopus and Web of Science databases.

Over the researched period of greatest demand towards circular bioeconomy are works on ecological aspect (Scopus - 25,1\% and Web of Science - 27,9\%) and energy (Scopus $16,9 \%$ and Web of Science - 28,8\%). However, a significant part of them is also considered from point of view of economics, management and business (Scopus - 8,2 \% and Web of Science $-3,5 \%$ ). In above-noted works the topic of circular bioeconomy predominates regarding strategic ambitions of some countries, political levers of sustainable 
world development and historical aspects of economic management on bioeconomy basis. Essential difference in number of works by separate branches between Scopus and Web of Science depends on possibility to identify one publication in several areas simultaneously and, at the same time, their ability to be differentiated by number in Web of Science database is slightly higher than in Scopus.

Until recently, Germany was the leader in number of publications at international level because it covered $11 \%$ of all publications around the world. At present, the first country is India, whose publications count 39 and 43 documents in Scopus and Web of Science respectively, which is almost $19 \%$ of the total number of publications in above-mentioned scientometric databases (Fig. 5).

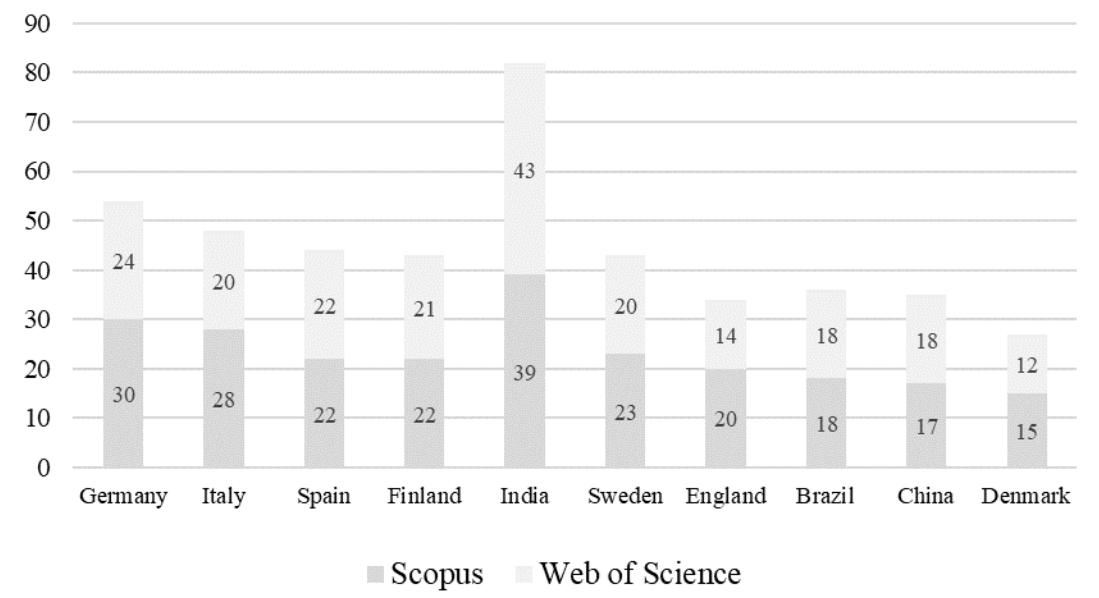

Fig. 5. Ranking of publications on Circular Bioeconomy at international level over the period of 2016-2020.

Source: built on data obtained from Scopus and Web of Science databases.

Geographical widespread is diverse as bioeconomy research is being carried out actively in Italy, Spain, France, Sweden, the UK, Brazil, etc. Scientists, in majority of developed countries, are trying to master the latest technologies of circular bioeconomy systems, to define their importance and role in overcoming global social and environmental challenges. Bibliographic analysis allows to identify the leading scientists who have the largest number of publications on circular bioeconomy over researched period (Table 2).

Table 2. Leading scientists in Circular Bioeconomy by number of publications in Scopus and Web of Science databases.

\begin{tabular}{|c|c|c|}
\hline \multirow{2}{*}{ Author } & \multicolumn{2}{|c|}{ Number of publications } \\
\cline { 2 - 3 } & Web of Science & Scopus \\
\hline Mohan S. V. [7] & 20 & 11 \\
\hline Pandey A. [8] & 6 & 5 \\
\hline D'Amato D. [6] & 6 & 6 \\
\hline Amulya K. [7] & 5 & - \\
\hline Sravan J.S. [9] & 5 & - \\
\hline Hemalatha M. [9] & 5 & 4 \\
\hline Dahiya S. [7] & 4 & 4 \\
\hline Ladu L. [10] & 3 & 4 \\
\hline Klitkou A. [5] & - & 4 \\
\hline Taherzaden M.J. [11] & - & 3 \\
\hline
\end{tabular}

Source: built on data obtained from Scopus and Web of Science databases. 
Important for Bioeconomy management evolvement are works of D. D'amato [6], associate professor of forestry at Helsinki Institute, whose key achievements are aimed at developing interconnected concepts of sustainable development. Other scientists' works deserve no less attention, as they cover deep analysis of updated conception, which is fundamental for further scientific studies in circular bioeconomy.

\section{Reviewing complementary interconnections of conceptions by keywords}

Systematization of leading scientists' publications allows to define main fields for research by keywords of circular bioeconomy. To make complementary interconnections between basic concepts we have used software VOSviewer, data for which is imported via CSV files from Scopus database (Fig. 6).

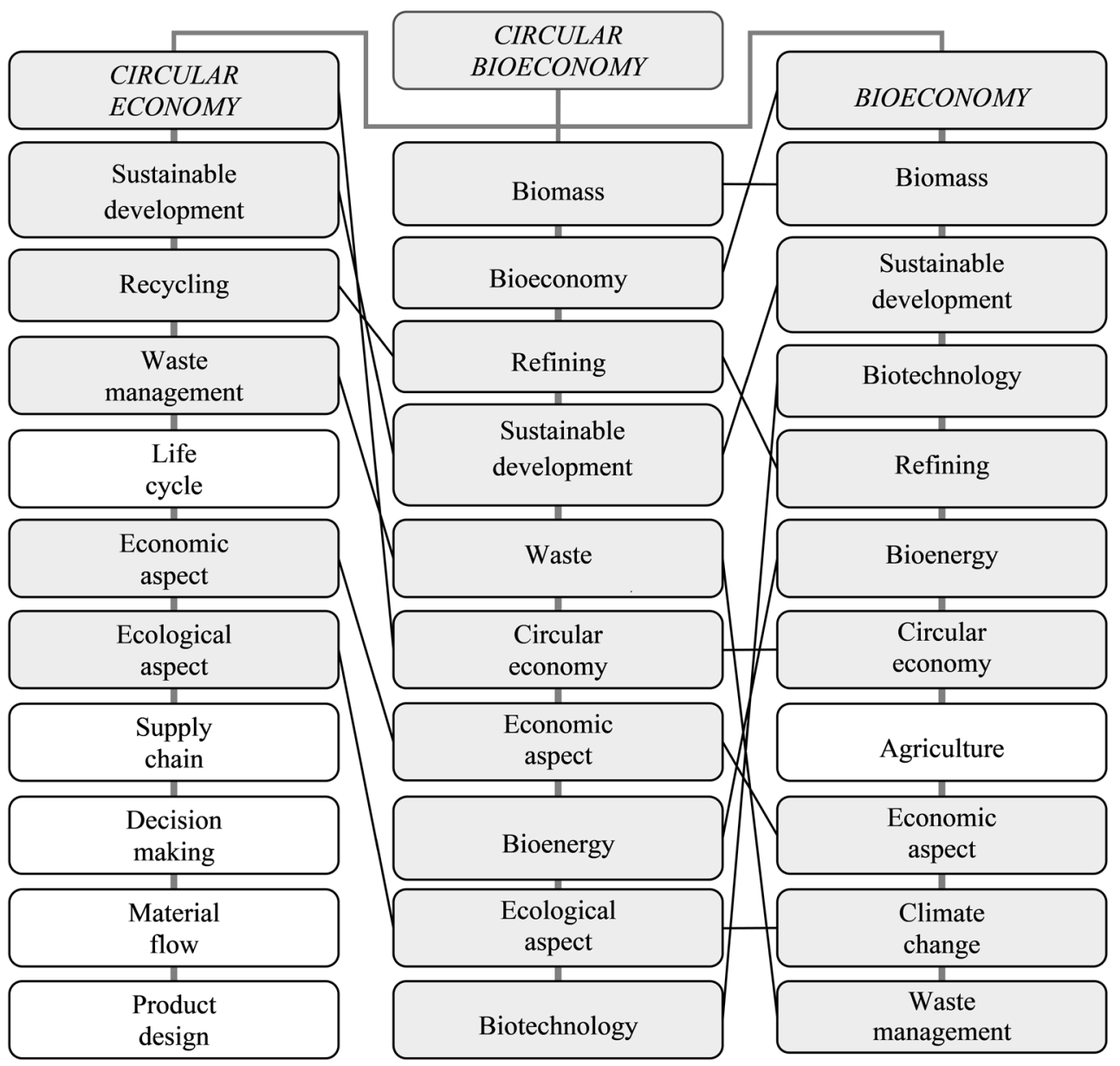

Fig. 6. Keywords for basic concepts of sustainable development in Scopus and Web of Science publications.

Source: Built using software VOSviewer. 
Study results have shown that 10 most widely used keywords from circular bioeconomy field are closely interconnected with bioeconomy conception, whose dominant basic concepts are: «biomass», "sustainable development» and «biotechnology». Therefore, circular economy distinguishes «sustainable development», «recycling» and «waste management», which highlights ecological aspect of circular bioeconomy. Keywords that are not highlighted in this figure show secondary importance in establishing complementary interconnections between concepts. Taking into consideration indirect influence, their importance in forming an integrating paradigm remains unchanged.

\subsection{Conception visualization by key words}

Abilities of software VOSviewer, developed by scientists [13] from the Center for Science and Technology Research at Leiden University (the Netherlands), allow to visualize scientific researches graphically, carried out on the basis of bibliometric data. (Fig. 7).

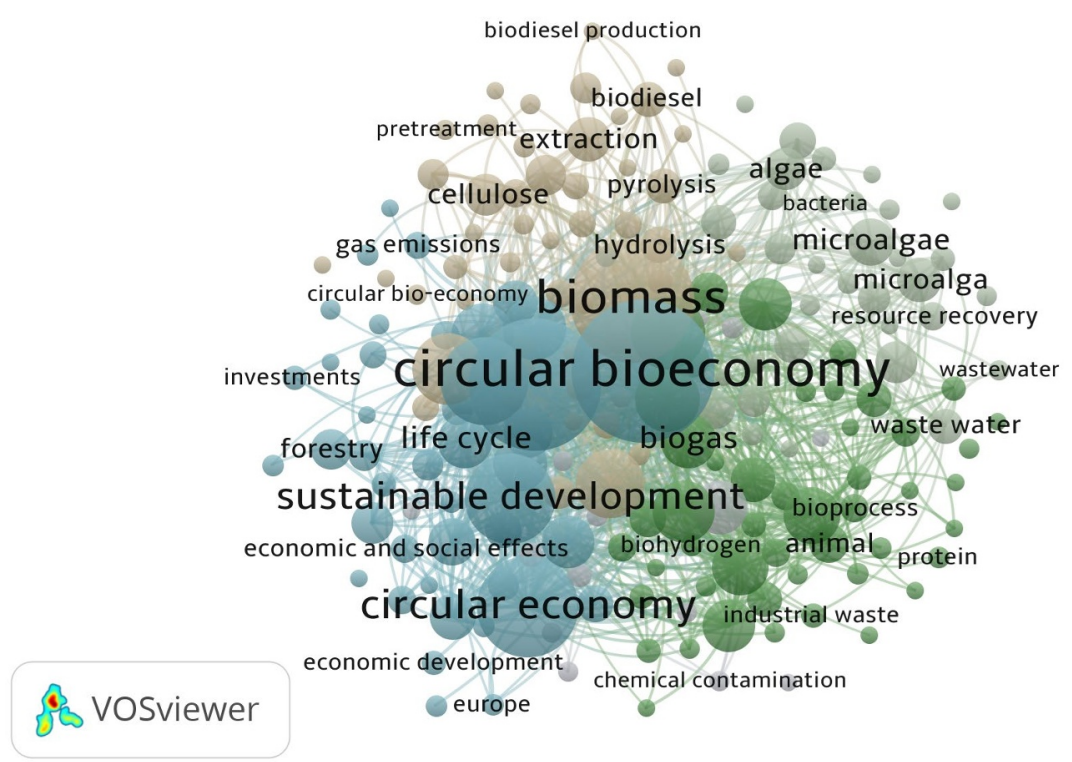

Fig. 7. Visualization of key terminology in the field of Circular Bioeconomy.

Source: built by author based on data obtained from scientometric database Scopus.

So, terminology map of circular bioeconomy contains keywords thematically divided into 4 clusters. For example, green colour reflects bioeconomy processes connected with biomass, blue colour concentrates on sustainable development, brown colour covers biotechnological processes, and grey is associated with microorganisms. Size of each circle in corresponding colour indicates number of publications, where keywords were used, the distance and linewidth show if the concepts are closely connected. Results on studying terminology in the field of bioeconomy is shown in Fig. 8. 


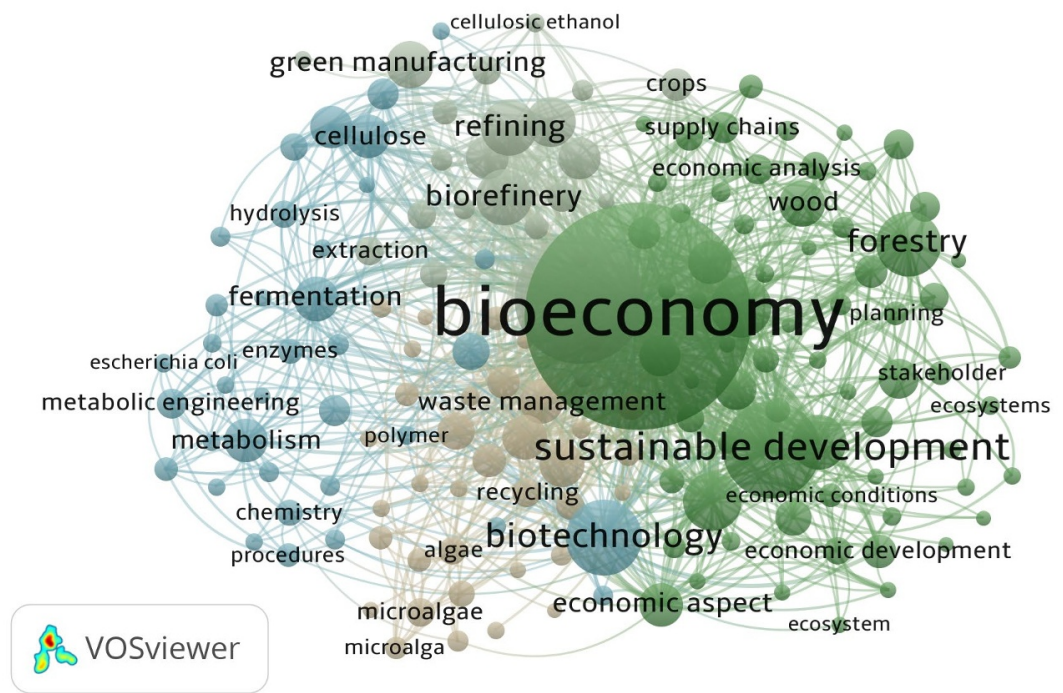

Fig. 8. Visualization of key terminology in the field of Bioeconomy.

Source: built by author based on data obtained from scientometric database Scopus.

In this case the biggest circle of bioeconomy is related to sustainable development, which responds to green cluster. Biotechnological developments occupy separate blue cluster, and brown covers processes of recycling and waste management. Biorefinery and green manufacturing are located at a short distance from bioeconomy, which indicates close connection between concepts identified in grey cluster. The terminology for the keywords of the circular economy is somewhat different, as the thematic focus covers 5 clusters.

Slightly different is keywords terminology of circular economy, as its thematic field occupies 5 clusters (Fig. 9).

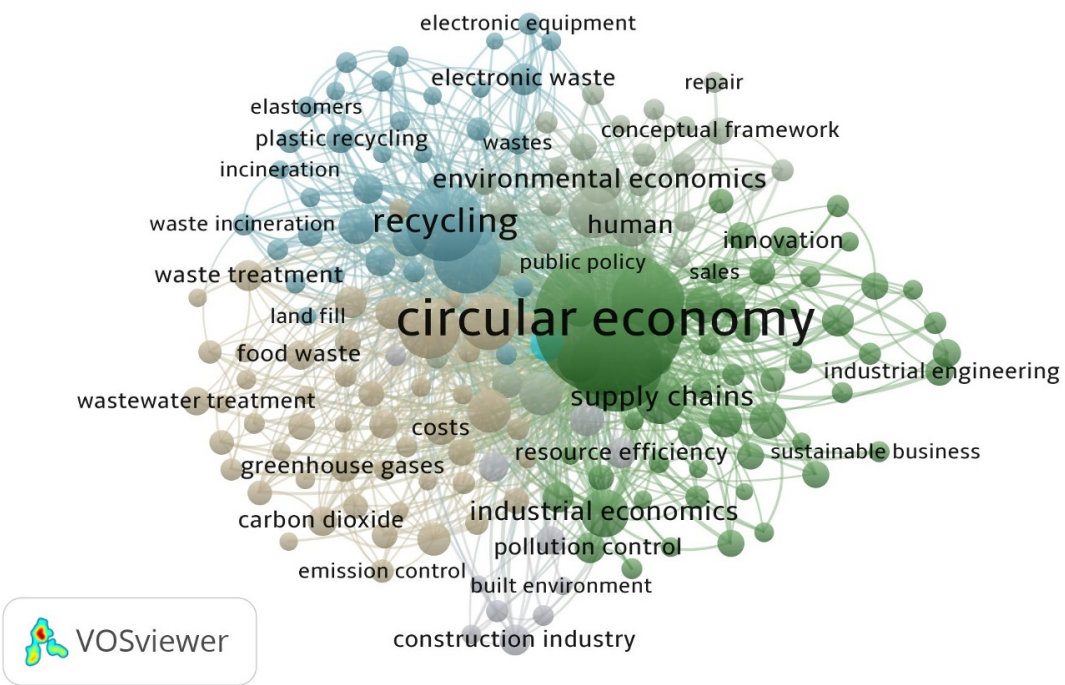

Fig. 9. Visualization of key terminology in the field of Circular Economy.

Source: built by author based on data obtained from scientometric database Scopus. 
Green sector contains concepts of industrial economics, sustainable business and resource efficiency. Blue colour unites words around the process of recycling and waste, grey colour is connected with human activity, studying theoretical ways of modelling circular business, brown colour covers ecological aspects, in particular greenhouse gases, wastewater treatment and emission control. Apart from these clusters there also exists the fifth one, which is caused by necessity to build new constructive environment, where construction industry appears as well as, closest to the circular bioeconomy, supply chains.

Bibliometric analysis of terminology allows to say about diversity of scientific research around circular bioeconomy issues. It is worth emphasizing how circular economy contributes to concept forming that reflects environmental aspect. Bioeconomy on the way to formation of circular bioeconomy is viewed through biomass and biotechnological developments, which creates basic foundation for integrative concept of sustainable development.

\section{Defining periods of circular bioeconomy evolution.}

The most widely used key words are definitions of circular and bioeconomy, which indicates their primary origin in scientific field, which preceded forming integrative concept of circular bioeconomy (Fig. 10).

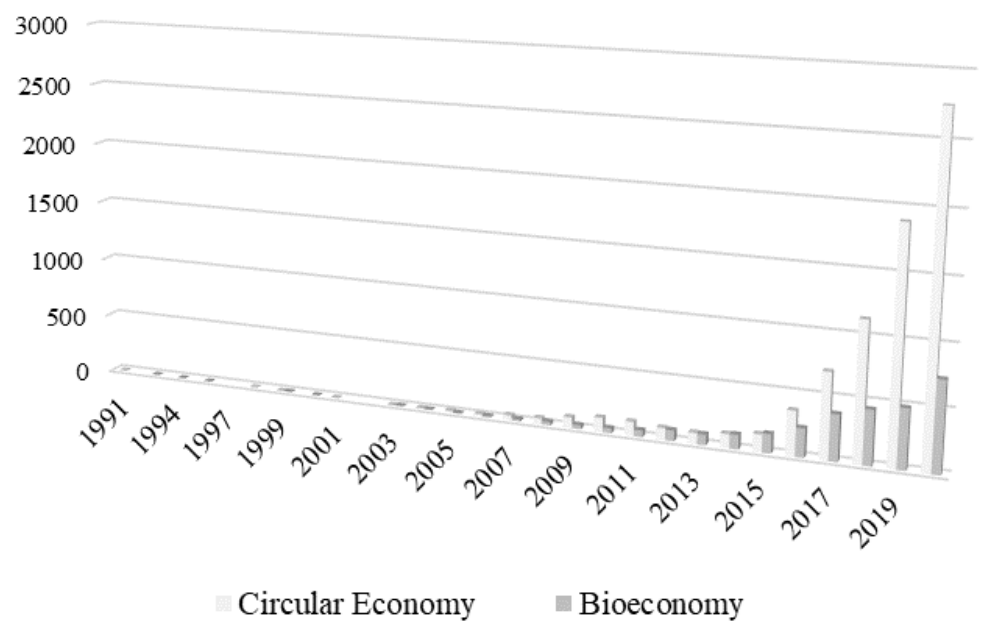

Fig. 10. Dynamics of scientific research of Circular and Bioeconomy.

Source: built by author based on data obtained from scientometric databases Scopus and Web of Science.

Gradual popularization of circular and bioeconomy at international level is explained by facilitated development of scientific and technological progress and constant increase of environmental challenges. At present, issues of circular and bioeconomy are prospering, as scientific papers have been growing more than 50\% annually since 2015 . First publications $[14,15]$ on circular economy appeared in Scopus database in 1991, while first scientific work [16] in Web of Science was published in 1998. Bioeconomy studies [17] in these databases were first published in 1992. Development of strategic initiatives and formation of bioeconomy policy in some developed countries facilitated growth of scientific discussions, which contributed to development of innovative business and modern concept emergence. 
Comprehensive consideration of scientific publications on bioeconomy enables to identify main periods of circular bioeconomy evolution, namely:

1) emergence period (from 1991 to 2004), which is marked by first works $[14,15]$ on circular economy (1991) and bioeconomy [17] (1992) in databases Scopus and Web of Science; presentation of bioeconomy [18] at the seminar of American Association for Advancement of Science (1997), development of conceptual framework of bioeconomy science;

2) transformation period (from 2005 to 2014), which is characterized by gradual increase in number of scientific papers in researched area (more than 10 Scopus and Web of Science databases); representation of updated economy conception based on biological knowledge at Brussels EU Conference [19] (2005); approval of strategic documents related to bioeconomy development in the framework of Organization for Economic Cooperation and Development (2009), European Commission (2012), the United States of America (2012);

3) advanced development (from 2015 up to the present) is characterized by rapid increase in works on circular bioeconomy in Scopus and Web of Science databases; categorical apparatus of circular bioeconomy and different approaches for its development are considered for the first time; active implementation of theoretical concepts in practice; raising public understanding of necessity to manufacture and consume products on biological basis.

\section{Conclusions}

Conception of circular bioeconomy is prospering, which is marked by active scientific publications proliferating, profound research and introduction of innovative developments in practice. This makes it possible to simultaneously manufacture products from renewable biological sources, neutralize harmful effects of management and minimize household and industrial waste. Thus, progressive growth of scientific publications on circular bioeconomy proves emergence of the latest integrated paradigm based on combination of basic concepts of circular and bioeconomy, whose implementation demonstrates great opportunities to overcome today's challenges and develop society in future.

\section{References}

1. Yaremova, M. (2020). Theoretical conceptualization of the problem of understanding bioeconomics. Scientific Horizons, 23(10), 78-87. https://doi.org/10.48077/scihor.23(10).2020.78-87

2. Mikhno, I., Koval, V., Shvets, G., Garmatiuk, O., \& Tamošiūnienè, R. (2021). Green Economy in Sustainable Development and Improvement of Resource Efficiency. Central European Business Review, 10(1), 99-113. https://doi.org/10.18267/j.cebr.252

3. Kostetska, K., Khumarova, N., Umanska, Y., Shmygol, N., \& Koval, V. (2020). Institutional qualities of inclusive environmental management in sustainable economic development. Management Systems in Production Engineering, 28 (2), 1522. https://doi.org/10.2478/mspe-2020-0003

4. Staffas, L., Gustavsson, M., \& McCormick, K. (2013). Strategies and Policies for the Bioeconomy and Bio-Based Economy: An Analysis of Official National Approaches. Sustainability, 5(6), 2751-2769. https://doi.org/10.3390/su5062751 
5. Bugge, M., Hansen, T., \& Klitkou, A. (2016). What Is the Bioeconomy? A Review of the Literature. Sustainability, 8(7), 691. https://doi.org/10.3390/su8070691

6. D'Amato, D., Droste, N., Allen, B., Kettunen, M., Lähtinen, K., Korhonen, J., Leskinen, P., Matthies, B.D., \& Toppinen, A. (2017). Green, circular, bio economy: A comparative analysis of sustainability avenues. Journal of Cleaner Production. 168, 716-734. https://doi.org/10.1016/j.jclepro.2017.09.053

7. Mohan, S. V., Butti, S. K., Amulya, J. A., Dahiya, K., \& Modestra, J. A. (2016). Waste Biorefinery: A New Paradigm for a Sustainable Bioelectro Economy. Trends in Biotechnology, 34(11), 852-855. https://doi.org/10.1016/j.tibtech.2016.06.006

8. Pandey, J. L. (2020). Policy for Bioeconomic Growth. BioScience, 70(6), 459-460, https://doi.org/10.1093/biosci/biaa049

9. Hemalatha, M., Sravan, J.S., Min, B., Mohan, S. V. (2019). Microalgae-biorefinery with cascading resource recovery design associated to dairy wastewater treatment. $\begin{array}{llll}\text { Bioresource technology, 284, 424-429. } & \text { 28 }\end{array}$ https://www.sciencedirect.com/science/article/abs/pii/S0960852419304699

10. Lokesh, K., Ladu, L., Summerton, L. (2018). Bridging the Gaps for a 'Circular' Bioeconomy: Selection Criteria, Bio-Based Value Chain and Stakeholder Mapping. Sustainability 2018, 10(6), 1695; https://doi.org/10.3390/su10061695

11. Taherzadeh, M., Bolton, K., Wong, J., Pandey, A. (2019). Sustainable Resource Recovery and Zero Waste Approaches, Elsevier.

12. Ioannidis, J. P. A., Boyack, K. W., \& Baas, J. (2020). Updated science-wide author databases of standardized citation indicators. PLOS Biology, 18(10), e3000918. https://doi.org/10.1371/journal.pbio.3000918

13. Van Eck, N.J., \& Waltman, L. (2020). VOSviewer Manual 1.6.14. 4, Universiteit Leiden; CWTS: Leiden, Netherland.

14. Leontief, W. (1991). The economy as a circular flow. Structural Change and Economic Dynamics, 2(1), 181-212. https://doi.org/10.1016/0954-349x(91)90012-h

15. Paul A. Samuelson. (1991). Leontief's 'the economy as a circular flow': An introduction. Structural Change and Economic Dynamics, 1(2), 177-179. https://doi.org/10.1016/0954-349X(91)90011-G

16. Iglhaut, L., Behmel, U., \& Meyer-Pittroff, R. (1998). Circular running economy with vegetable oils. In: Proc. 10th Eur. Conf. Technol. Exhib., Biomass for Energy and Industry, Würzburg, Germany, 568-571.

17. Berry, R. J., \& Bronson, F. H. (1992). Life History and Bioeconomy of the House Mouse. Biological Reviews, 67(4), 519-550. https://doi.org/10.1111/j.1469185x.1992.tb01192.x

18. Enriquez, J. (1998). Genomics and the World's Economy. Science, (281), 925-926. https://doi.org/10.1126/science.281.5379.925

19. Potochnik, J. (2005). Transforming life sciences knowledge into new, sustainable, ecoefficient and competitive products. Conference Report. Brussels, Belgium. https://ec.europa.eu/commission/presscorner/detail/en/SPEECH $05 \quad 513$ 